\title{
Brain Size: A Global or Induced Cost of Learning?
}

\author{
Emilie C. Snell-Rood ${ }^{\mathrm{a}}$ Daniel R. Papaj ${ }^{\mathrm{a}}$ Wulfila Gronenberg ${ }^{\mathrm{b}}$ \\ a Department of Ecology and Evolutionary Biology and bArizona Research Laboratories, Division of Neurobiology, \\ University of Arizona, Tucson, Ariz., USA
}

\section{Key Words}

Mushroom body $\cdot$ Brain size $\cdot$ Antennal lobe $\cdot$ Learning .

Butterfly · Pieris rapae

\begin{abstract}
The role of brain size as a cost of learning remains enigmatic; the nature and timing of such costs is particularly uncertain. On one hand, comparative studies suggest that congenitally large brains promote better learning and memory. In that case, brain size exacts a global cost that accrues even if learning does not take place; on the other hand, some developmental studies suggest that brains grow with experience, indicating a cost that is induced when learning occurs. The issue of how costs are incurred is an important one, because global costs are expected to constrain the evolution of learning more than would induced costs. We tested whether brain size represented a global and/or an induced cost of learning in the cabbage white butterfly, Pieris rapae. We assayed the ability of full sibling families to learn to locate either green hosts, for which butterflies have an innate search bias, or red hosts, which are more difficult to learn to locate. Naïve butterflies were sacrificed at emergence and congenital brain volume estimated as a measure of global costs; experienced butterflies were sacrificed after learning and change in brain volume estimated as a measure of induced costs. Only for the mushroom body, a brain region involved
\end{abstract}

in learning and memory in other insects, was volume at emergence related to learning or host-finding. Butterfly families that emerged with relatively larger mushroom bodies showed a greater tendency to improve their ability to find red hosts across the two days of host-search. The volume of most brain regions increased with time in a manner suggesting host experience itself was important: first, total number of landings during host-search was positively related to mushroom body calyx volume, and, second, experience with the red host was positively related to mushroom body lobe volume. At the family level, the relative volume of the mushroom body calyx and antennal lobes following learning was positively related to overall success in finding red hosts. Overall, our results suggest that within species, brain size might act as a small global cost of learning, but that environment-specific changes in brain size might reduce the overall costs of neural tissue in the evolution of learning.

Copyright $\odot 2009$ S. Karger AG, Basel

\section{Introduction}

Brain size has been hypothesized to be an important factor in the evolution of learning [reviewed in Johnston, 1982; Dukas, 1998]. Neural tissue is metabolically expensive [Laughlin et al., 1998]; if more neural tissue is re-

\section{KARGER}

(ㅇ) 2009 S. Karger AG, Basel

Fax +41613061234

E-Mail karger@karger.ch

www.karger.com
Accessible online at: www.karger.com/bbe
Emilie C. Snell-Rood

Department of Biology, Indiana University

915 E. Third St.; Myers Hall, Rm 150

Bloomington, IN 47405 (USA)

Tel. +1 812856 1783, Fax +1 812855 6705, E-Mail emcsnell@indiana.edu 
quired to learn and remember, then the cost of such tissue might constrain the evolution of learning. There is some evidence that better learning requires a larger brain relative to an ancestor. For example, comparative studies across vertebrates suggest a consistent linkage between learning ability and the relative size of brains or brain regions. Spatial learning capacity is linked to hippocampus size in birds and mammals [e.g., reviewed in Sherry et al., 1992; Basil et al., 1996; Healy and Krebs, 1996], and song learning ability in birds is linked to the volume of song control regions of the brain [e.g., DeVoogd et al., 1993; Brenowitz et al., 1995; reviewed in DeVoogd, 2004]. Several comparative studies of insects also suggest that the size and complexity of brain regions such as the mushroom bodies are linked with the evolution of feeding behaviors that might involve learning [Sivinski, 1989; Farris and Roberts, 2005].

Theory suggests that the costs of brain size might differentially affect the evolution of learning, depending on how such costs are incurred. If increases in learning ability require corresponding increases in congenital brain size - investment even before learning takes place - the associated costs of that increased neural investment will be high. Such global costs are paid in all environments and contexts, regardless of how much learning actually takes place [Johnston, 1982; Dukas, 1998; e.g., Pitnick et al., 2006; Isler and van Schaik, 2006a, b]. This means that a cost of learning might sometimes be paid even when the benefits of learning are not realized. In contrast, costs of learning might not be global, but rather induced in specific environments. If relatively large brains or brain components could be produced only in environments or contexts in which learning has benefits (a 'pay as you go' pattern of investment), the cost of brain size could be greatly reduced, and learning consequently more likely to evolve and be maintained [Tollrain, 1995; DeWitt et al., 1998].

Studies of vertebrate and invertebrate species alike suggest that neural tissue increases in volume over the course of experience, suggesting that neural tissue itself could also act as an induced cost. For instance, the mushroom bodies, regions of the insect brain involved in sensory integration and learning [reviewed in Strausfeld et al., 1998; Zars, 2000], show increases in size and complexity that are in part coincident with, but also dependent on, learning and experience [Withers et al., 1993, 2007; Gronenberg et al., 1996; Fahrbach et al., 1998; Farris et al., 2001; Ismail et al., 2006]. Similarly, in vertebrates, regions of the brain involved in spatial and song learning show changes in size that coincide with seasonal use [reviewed in Tramontin and Brenowitz, 2000; Sherry, 2006]. Increases in neural investment are also associated with rearing in complex or activity-promoting environments [e.g., Nilsson et al., 1999; Scotto-Lomassese et al., 2000; reviewed in van Praag et al., 2000; Cotman and Berchtold, 2002] or with learning itself [Clayton and Krebs, 1994].

We know of no study that has tried to assess the relative importance of congenital brain size simultaneously with induced brain size as costs in the evolution of learning. In this study, we sought to make this assessment with respect to host-learning in ovipositing butterflies. We adopted a family-level approach in which full-sib families of butterflies were reared, mated and provided egg-laying experience with host plants in a semi-natural setting. Such a family-level approach offered several advantages. First, a link found between learning and brain size within species can more reasonably be considered to reflect cause and effect than with species comparisons. Inference in phylogenetic studies is necessarily constrained by the multitude of factors that could have changed between species in the time since their most recent common ancestor. Any number of these factors could be driving a correlation between learning and brain size. Second, the family-level approach, as applied here, can give us an estimate of the amount of genetic variation in extant populations in brain size and brain development. The structure of variation can inform us regarding how learning ability and associated brain traits might evolve under selection. Finally, the family-level approach was used for an important logistical reason. For insects as small as butterflies, we presently lack a non-destructive technique by which to assess brain size before learning. By splitting full-sib families into groups whose brain size at emergence was estimated and groups whose learning ability was assayed, we were able to estimate a correlation between learning ability and congenital brain size.

We addressed the question of learning and brain size using host-learning in butterflies. Butterflies possess innate biases to search for and use host and nectar resources, but they also have the capacity to learn to recognize, locate, and physically manipulate additional host plants and nectar sources [reviewed in Papaj and Prokopy, 1989; Traynier, 1984, 1986; Lewis, 1993; Papaj and Lewis, 1993; Hern et al., 1996; Kandori and Ohsaki, 1996; Papaj, 2003]. Host cues such as color, shape, size, and odor are learned through a trial-and-error process, in which individual butterflies sample plants by landing on them and identifying them as hosts or non-hosts through contact chemoreception [reviewed in Courtney, 1986; Renwick and Chew, 1994; Hern et al., 1996]. 
We specifically evaluated host-learning in adults of the cabbage white butterfly, Pieris rapae. The life history and diet of this species allowed us to raise enough individuals from a genetic unit (family of full siblings) to determine whether learning is correlated either with brain size at emergence or brain size following learning. Pieris rapae and the closely related Pieris brassicae are innately biased to search for green hosts, but can learn to associate other colors with the presence of glucosinolates, phytochemicals that are found in their hosts, members of the plant family Brassicaceae [Kolb and Scherer, 1982; Hern et al., 1996].

Several regions of the butterfly brain are thought to be important in learning to locate host plants. First, learning itself is thought to involve the mushroom bodies, central multi-sensory brain components that have been shown to play a critical role in the integration of different cues and in insect learning more specifically [Strausfeld et al., 1998; Zars, 2000; Huerta et al., 2004]. The mushroom body calyces receive input from sensory areas, especially olfactory regions [Strausfeld et al., 1998], but also sometimes visual regions [Mobbs, 1982; Gronenberg, 2001]. The principal mushroom body neurons, the Kenyon cells, project from the calyces to the mushroom body lobes, where they subsequently synapse with output neurons connecting to other regions of the brain [although there are also some inputs into the lobes; Strausfeld et al., 1998; Farris and Sinakevitch, 2003]. Second, learning to locate host plants also relies on sensory and motor regions of the brain. Olfactory and visual cues, both important in butterfly host-search [Courtney, 1986; Renwick and Chew, 1994; Hern et al., 1996], are processed in sensory input regions, in particular the antennal lobe (olfaction) and the optic lobes (the visual centers of the lamina, medulla and lobula; see figure 1a-d). In addition, motor coordination is important for locating specific plants during hostsearch (e.g., through hovering, rapid turning). Hence, our study also included the central body, a region of the insect brain presumed to be important in motor control and coordination [Strauss and Heisenberg, 1993; Strausfeld, 1999], visual learning [Liu et al., 2006] and spatial orientation [Heinze and Homberg, 2007]. We predicted that within the butterfly species $P$. rapae, a family's brain size and mushroom body size at emergence would be correlated with learning ability (global costs). We also predicted that several brain regions important in learning to locate hosts - sensory, motor, and integrative regions would show specific responses to the host-learning experience (induced costs).

Brain Size: A Global or Induced Cost of Learning?

\section{Materials and Methods}

Overview of Experimental Design

Female butterflies were collected from populations in six states across the United States. Offspring were collected and reared on an artificial diet under controlled conditions using established methods [Troetschler et al., 1985; Webb and Shelton, 1988; Snell-Rood and Papaj, in press]. In our first experiment, siblings were allocated upon emergence to independent treatment groups. One group was sacrificed at emergence, and the heads fixed and preserved at that time for later analysis. Four other groups were transported to greenhouse cages for two days of experience with other butterflies, including mating, and with nonhost flowering plants, before being allowed to search for hosts. Individual butterflies were then allowed to search for at least $2 \mathrm{~h}$ for hosts (either red or green hosts in either a simple or complex non-host environment) over two consecutive days, after which they were sacrificed and their head preserved for later analysis. Butterflies were sacrificed 4-6 h following their final host experience; during this time they were held in a small flight cage with access to honey water, and then transported from the greenhouse at roughly $4^{\circ} \mathrm{C}$.

In a subsequent experiment that focused on color learning and energy allocation ['Experiment 2'; Snell-Rood and Papaj, in press], we also collected brains from butterflies at emergence and just prior to learning (the primary focus of the experiment precluded collecting brains following learning). Using these brains, we addressed two additional questions. First, we included both red and green non-hosts in the learning assay to determine whether correlations between brain size at emergence and learning were due to color learning per se. Color choice could be assayed as the proportion of non-host landings on green non-hosts (versus red nonhosts). Second, we sacrificed butterflies both at emergence and just prior to learning (following two days of experience in the greenhouse without hosts) to try to assay the degree of developmental changes in brain size that were dependent on host-learning.

Measurement of Learning Ability

Host-Search Behavior and Its Quantification. A butterfly's learning sequence was constructed based on observations of tarsal drumming and oviposition on host and non-host plants. Hostsearch is characterized by a stereotypical pattern of fluttering flight interspersed by landings on foliage. Upon landing, a female typically drums her foretarsi, a behavior thought to be associated with contact chemoreception using tarsal receptors. If the plant is a non-host, a female invariably takes flight and resumes search. If the plant is a host, females might or might not lay a single egg before taking flight and resuming the search.

Learning was measured as a function of host-finding efficien$\mathrm{cy}$, the proportion of hosts chosen over all landings during a particular time interval. Host-finding efficiency was measured in relation to bins of ten landings in order to define the time course of changes in host-finding efficiency. As an example, a butterfly that made 5 host landings would receive, for that bin of ten landings, a host-finding efficiency score of $0.5(5 / 10)$; the greater the proportion, the more successful a female was in discriminating hosts from non-hosts before landing. Learning was inferred as an improvement in host-finding efficiency over time. 'Within-day' change was measured as the difference in behavior between the 
first and second set of ten landings on the first day of learning. 'Between-day' change was measured as the difference in behavior between the first ten landings over the two days of learning. We also measured total fitness as the number of total hosts located while controlling for the number of total landings during hostsearch (over both days of learning).

In the subsequent Experiment 2, learning was measured as a function of color choice, defined as the proportion of green nonhosts chosen over red non-hosts during a particular time interval. As an example, a butterfly that made 3 landings on green nonhosts and 2 landings on red non-hosts would receive a color choice score of $0.6(=3 / 5)$. Within- and between-day changes in color choice were measured as in Experiment 1, as the difference between the first and second bins of ten landings on day 1 , and the difference between the first ten landings over the two days of learning, respectively. Color learning was thus inferred as an increase in the proportion of non-host landings that were made on the same color as the host plant to which females were exposed (positive values of changes in color choice = learning green; negative values of changes in color choice = learning red).

Because it is standard for proportional data, all measures of choice were arcsine-square root transformed prior to analysis. Raw proportion values are presented in figures.

Learning Assays. Experiment 1 (June-September 2005), from which the majority of the results come, was designed to assess learning of two very different hosts. Butterflies were members of seven first-generation full-sibling families that originated from females collected from five populations across the United States (NV, MI, MA, northern and southern CA). Individuals from each family were sacrificed at emergence or just after two successive days of host experience. After emergence, butterflies destined for learning trials were kept for two days in a $1 \mathrm{~m}^{3}$ greenhouse cage with other butterflies and non-host nectar plants, and then allowed to search for hosts for $2 \mathrm{~h}$ over each of two days in a $2 \mathrm{~m}$ tall $\times 4 \mathrm{~m}$ wide $\times 4 \mathrm{~m}$ long greenhouse flight cage. Butterflies were sacrificed (and fixed) $4-6 \mathrm{~h}$ following their final host experience; during this time they were held in a small flight cage with access to honey water, and then transported from the greenhouse at roughly $4^{\circ} \mathrm{C}$.

We used a greenhouse array of live plants to assay host-learning as this design was both ecologically relevant, and encouraged a large enough number of butterflies to participate in learning trials. A large sample size was crucial to obtaining information about family-level effects. This experiment tested butterfly learning of two hosts, one green in color (kale, Brassica oleracea var. viridis), and one red (Barbarea vulgaris grown in the sun) that differed in color, leaf shape and presumably chemical cues. Color differences among hosts and non-hosts were verified using an Ocean Optics USB2000 spectrophotometer with a halogen light source and Spectralon reference standard. In this experiment, butterflies had to learn to locate hosts in either a simple or complex non-host environment. The simple environment contained eight hosts and eight green non-hosts of one species (seep monkeyflower, Mimulus guttatus: Scrophulariaceae). The complex treatment contained four hosts and 16 green non-hosts, four each of seep monkeyflower, creeping phlox (Phlox subulata: Polemoniaceae), window-box wood sorrel (Oxalis rubra: Oxalidaceae), and white-veined Dutchman's pipe (Aristolochia fimbriata: Aristolochiaceae).

Experiment 2 (June-September 2006) was designed to test whether improvement in host-finding efficiency (and associa- tions with brain size) was due in part to color learning [SnellRood and Papaj, in press]. We used red and green varieties of the same host species (cabbage, Brassica oleracea var. capitata: Brassicaceae); we used red and green varieties of non-hosts to assay the colors to which females were attending during host-search. In this experiment, four families were first-generation full sibling groups originating from field-collected females from two populations (NY, Southern CA); three lines originated from laboratory-reared third-generation offspring derived from several field-collected females from two populations (AZ, northern CA). Butterflies searched for hosts $(n=8)$ within an array of non-hosts $(n=40)$. The simple non-host environment consisted of red and green varieties of ligularia (Ligularia dentata: Asteraceae); the complex treatment consisted of red and green varieties of ligularia, red and green varieties of basil (Ocimum basilicum: Lamiaceae), red and green varieties of swiss chard (Beta vulgaris var. cicla: Amaranthaceae), red and green species of oxalis (Oxalis stricta, O. rubra: Oxalidaceae), and red and green varieties of Ipomea vine (Ipomea batatas: Convolvulaceae). Color differences among hosts and non-hosts were verified using an Ocean Optics USB2000 spectrophotometer with halogen light source and Spectralon reference standard [Snell-Rood and Papaj, in press]. In this experiment, brains from 19 individuals sacrificed at emergence were measured. Additionally, six individuals were sacrificed following two days of experience (without hosts) in greenhouse cages, just prior to when other butterflies started learning.

\section{Measurement of Brain and Brain Region Size}

Histology. Butterflies were decapitated, and heads prepared for fixation by removing antennae and mouthparts, and cutting a hole in each eye to allow for the penetration of fixative. Heads were fixed in $4 \%$ formaldehyde in phosphate buffer ( $\mathrm{pH}$ 6.9) for $24 \mathrm{~h}$ and then transferred to cacodylate buffer and stored at $4^{\circ} \mathrm{C}$ until dissection.

Brains were dissected and stored in cacodylate buffer at $4^{\circ} \mathrm{C}$ until staining. They were then impregnated in the dark with $1 \%$ aqueous osmium tetroxide solution for $2 \mathrm{~h}$ at $4^{\circ} \mathrm{C}$ and an additional $30 \mathrm{~min}$ at room temperature, then rinsed with distilled water $(15 \mathrm{~min})$ and dehydrated with $15 \mathrm{~min}$ rinses of $50 \%$ ethanol and acidified 2,2-dimethoxypropane [Thorpe and Harvey, 1979], followed by two $15 \mathrm{~min}$ rinses of acetone. Brains were then em-

Fig. 1. Brain of Pieris rapae. a, b Three-dimensional graphical reconstruction (a dorsal view, b frontal view tilted sideways) incorporating 41 drawings each representing $15 \mu \mathrm{m}$; c, d Photomicrographs (dorsal views) showing ventral (c) and dorsal aspects (d); each half image is a photomontage of 2-3 osmium-stained sections. e Photomicrograph showing neuronal processes labeled by tracer injection into the medulla/lobula transition zone. Inset (enlarged in f) reveals visual input fibers from the medulla terminating in the mushroom body calyx. al = Antennal lobe; $\mathrm{ca}=$ mushroom body calyx; $\mathrm{cb}=$ central body; es = esophagus; la = lamina; lo = lobula complex; $\mathrm{mbl}=$ mushroom body lobes; $\mathrm{me}=$ medulla; pe $=$ mushroom body peduncle; pot $=$ posterior optic tubercle; seg = subesophageal ganglion. 

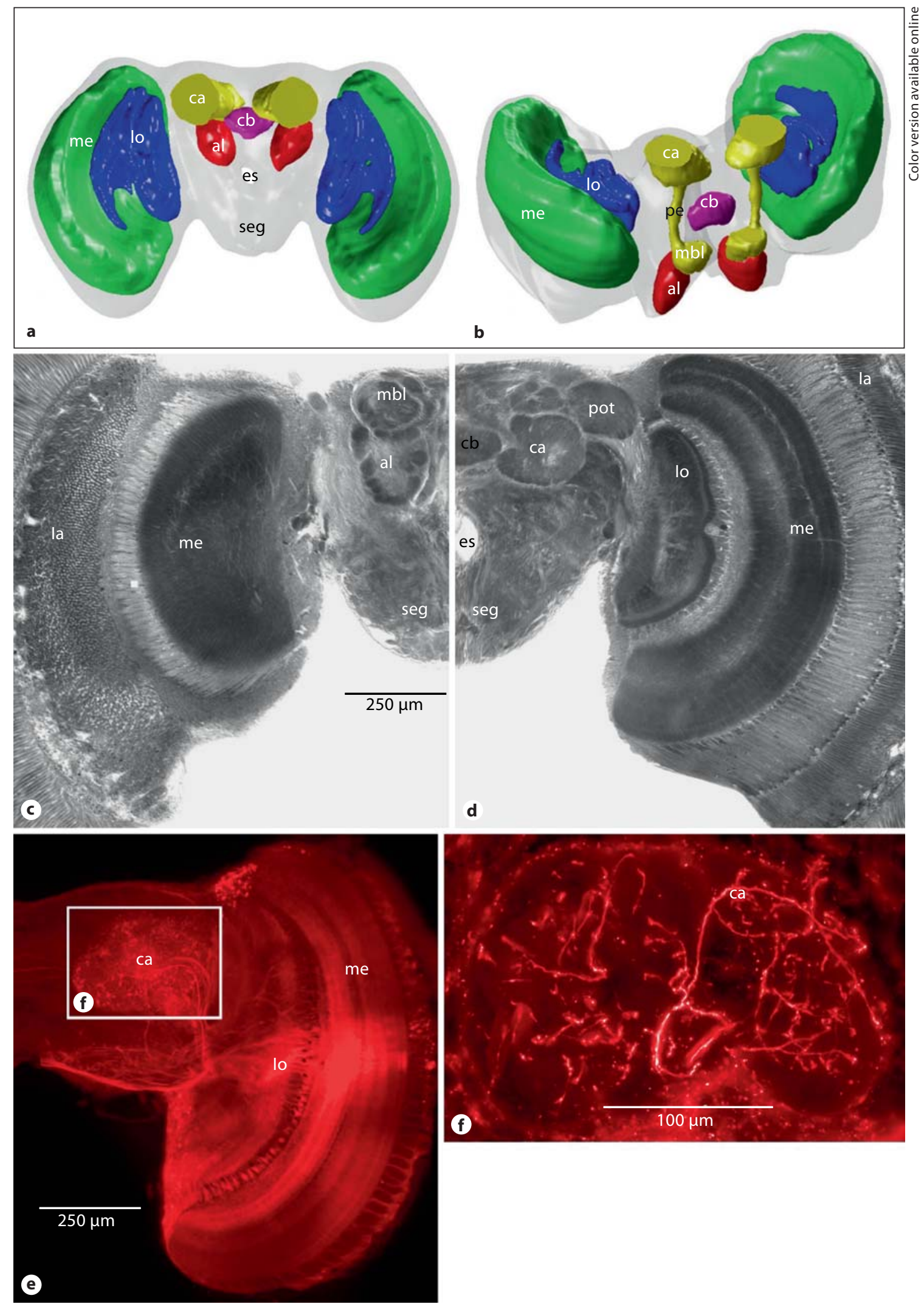
bedded in plastic (Spurr's low viscosity medium, EMS, Hartfield, PA) by treating with 7:3 plastic:acetone for $12 \mathrm{~h}$, followed by treatment with $100 \%$ plastic for $12 \mathrm{~h}$. Blocks were polymerized at $65^{\circ} \mathrm{C}$ for $12 \mathrm{~h}$, then serially sectioned at $10-15 \mu \mathrm{m}$ thickness on a sliding microtome. Sections were mounted and cover-slipped.

\section{Brain Regions and Measurements}

Brains were viewed with Nomarski interference contrast on a Zeiss Axioplan microscope and images were photographed using a SPOT 2 digital camera (Diagnostic Instruments, Sterling Heights, Mich., USA). A three-dimensional model of the brain (fig. 1a, b) was generated from traced brain outlines using a selfcompiled MatLab routine (Mathworks, Natick, Mass., USA).

We measured the brain and brain regions using ImageJ software (NIH). All regions except the central body (which was measured in its entirety) were measured in one hemisphere only (thus final volume estimates were multiplied by two). The mushroom bodies, central body, and antennal lobe (see fig. 1) were traced from every section when present. The medulla and whole brain were traced from every other section as they were present in almost all sections for each individual (on average 40 sections per individual; thus final volume estimates were multiplied by two). The antennal lobes were measured as the sum of the volumes of glomeruli only. For a given section, the volume of each region was estimated as the area in the section times the section thickness. This protocol [Mares et al., 2005] generates volume data as accurate as those of the 'Cavalieri' method, a standard morphometric technique in vertebrates [Gundersen and Jensen, 1987; Michel and Cruz-Orive, 1988].

Much of our analysis focused on measurements of the mushroom bodies which play a role in insect learning [Strausfeld et al., 1998; Zars, 2000; Huerta et al., 2004]. The mushroom bodies of Pieris consist of the calyx, consisting of two fused saucer-like structures located posterior and dorsal in the butterfly brain, and the anteriorly-located lobes [Nordlander and Edwards, 1968; Pearson, 1971; Ali, 1974]. These two parts are connected by a thin stalk, which can be seen in figure $1 \mathrm{~b}$, but which was not included in our measurements because of its small size. Our measurements focused on the calyces and the lobes, which were the most easily delineated parts of the mushroom body. Mushroom body lobes have several parts in the Lepidoptera [e.g., alpha, beta, gamma; Pearson, 1971; Ali, 1974], but are not easy to discriminate, thus we measured the lobes together.

The calyx receives prominent olfactory input in most insects [Strausfeld et al., 1998]. To test whether the Pieris calyx also receives visual input, as in other species in which visual learning is important [for example, members of Order Hymenoptera; Mobbs, 1982; Gronenberg, 2001], we labeled visual neurons in the medulla using fluorescent tracer (fluoro-ruby; Invitrogen, Carlsbad, Calif., USA). The head capsule was opened above the medulla, and tracer then applied to the exposed tissue using a glass microelectrode covered with a few tiny tracer crystals. The tracer was then allowed to diffuse into the tissues of the live butterfly for $4-8 \mathrm{~h}$, after which the animal was killed and the brain removed, fixed, plastic-embedded and sectioned as described above. Visual input neurons (fig. 1e, f) were photographed (Spot 2 camera) using conventional fluorescence microscopy and dichroic excitation/emission filters appropriate for fluoro-ruby. To reveal neurons in their entirety, individual images were merged using Photoshop 5 software (Adobe, San Jose, Calif., USA).
Body Size and Relative Brain (and Brain Region) Size

The size of brain regions was measured relative to whole brain size by including whole brain volume as an independent variable in every ANOVA that considered the size of a brain region (see tables $3-8$ ). In analyses of whole brain volume, we included hindwing area as an independent variable to control for body size. We chose hindwing area as a proxy for body size after recording several measures of body size for each individual. Wings were removed and photographed with a macro lens (Canon EOS Digital; $50 \mathrm{~mm}$ lens); the area of forewing and hindwing were measured using ImageJ. The legs of butterflies were photographed using a stereo microscope. The length of the tarsus on each leg was measured and averaged across the fore-, mid-, and hind-tarsi. Finally, the dry mass of the thorax was weighed to the nearest $0.1 \mathrm{mg}$. A principal components analysis on a subset of the individuals $(\mathrm{n}=$ 68) revealed that all measures of body size were highly correlated: the first principal component explained $57.9 \%$ of the variance among forewing area, hindwing area, tarsus length, and thorax mass (relative loadings: $0.62,0.61,0.25,0.42$, respectively). Because hindwing area was highly correlated with mass and tarsus length, and was least likely to be damaged on experienced butterflies, it was adopted as the proxy for body size in our analysis.

\section{Analyses}

JMP 7 (SAS Institute) was used for all analyses. First, for Experiment 1, we performed several analyses to test for changes in behavior over time, as in Snell-Rood and Papaj [in press]. We used $\mathrm{t}$ tests to determine whether host-finding efficiency changed significantly over time (i.e., whether the difference in behavior between two time bins was significantly different from zero). We used ANOVA to test whether host color and non-host complexity had effects on host-finding efficiency for each time bin considered. We restricted this latter analysis to only those individuals that had participated for at least 20 landings on day 1 and 10 landings on day 2 of host-search; such participation criteria minimize the confounding effects of population-level (instead of individual-level) changes in behavior over time.

Second, we performed family-level analyses of brains and behavior. A family's brain size was estimated as the least-square mean from ANOVA models that controlled for body size (in the case of whole brain size) or whole brain size (in the case of brain region size). We estimated a family's learning and behavior from ANOVA models, as described in Snell-Rood and Papaj [in press]. Briefly, mixed model ANOVAs were constructed, where 'host color' and 'non-host complexity' were treated as fixed effects, and 'family' and 'host color by family' were treated as random effects [Fry, 1992]. We used least-square means of the 'host color by family' interaction to estimate host-finding efficiency and color choice specific to each environment (in Experiment 1 and 2, respectively). Because these analyses were performed at the family level, power in statistical tests was greatly reduced, despite measurement of over 85 individual brains; thus, we consequently attach weight to $\mathrm{p}$ values as high as 0.10 .

Finally, we used ANOVA to determine the effects of experience on brain size. In these analyses, we compared brains from individuals sacrificed at different time points, or the effects of experience (e.g., host color, number of landings) on brain size following host experience. 
Table 1. Changes in host-finding performance over time

\begin{tabular}{|c|c|c|c|c|}
\hline & \multicolumn{2}{|l|}{ Green host } & \multicolumn{2}{|l|}{ Red host } \\
\hline & simple & complex & simple & complex \\
\hline Within day 1 & $\mathrm{t}_{32}=7.10^{* * *}$ & $\mathrm{t}_{29}=3.06^{* *}$ & $\mathrm{t}_{36}=4.69^{* * *}$ & $\mathrm{t}_{40}=6.33^{* * * *}$ \\
\hline Between days & $\mathrm{t}_{27}=3.78^{* *}$ & $\mathrm{t}_{28}=2.22^{*}$ & $\mathrm{t}_{34}=4.67^{* * *}$ & $\mathrm{t}_{29}=4.03^{* *}$ \\
\hline
\end{tabular}

\section{Results}

\section{The Brain of Pieris rapae}

The antennal lobes (glomeruli only) of the Pieris rapae brain were rather small in size $\left(0.007 \mathrm{~mm}^{3}\right.$ on average, $1.5 \%$ of the total brain volume; Appendix 1), despite the importance of olfactory cues in host plant and nectar plant use. In contrast, the size of the visual system (the lamina, medulla and lobula complex; fig. 1c, d; only the latter two are rendered in fig. 1a, b) greatly surpasses that of other sensory neuropiles or even the entire central brain for P. rapae; the size of the medulla alone averaged $0.19 \mathrm{~mm}^{3}$ (almost half of the size of the average whole brain, $0.47 \mathrm{~mm}^{3}$; Appendix 1). The central body was the smallest brain component examined (at $0.002 \mathrm{~mm}^{3}$, fig. 1a, b, d; Appendix 1).

The mushroom bodies were of moderate size in $P$. rapae: the calyces and vertical lobes averaged $0.007 \mathrm{~mm}^{3}$ and $0.004 \mathrm{~mm}^{3}$, respectively; together, the mushroom bodies took up about $2.4 \%$ of the total brain volume. We found that, besides massive olfactory input [Strausfeld et al., 1998], the $P$. rapae calyx also receives visual input, as revealed by the tracer injections (fig. 1e, f). This particular example (fig. 1e, f) shows one or two visual neurons originating from the medulla and supplying the mushroom body calyx, revealing the extensive branching pattern of these individual neurons. Tracer injections into larger or different areas of the medulla showed that the calyx receives a multitude of visual input neurons (probably also including visual input from the lobula, which was not examined in the current study).

\section{Effect of Host Experience on Host-Search}

Butterflies showed significant increases in host-finding efficiency over time. In time-binned data, the proportion of landings on host plants increased significantly over time, both within the first day of host-search and between the two days of host-search (table 1; fig. 2). Host-

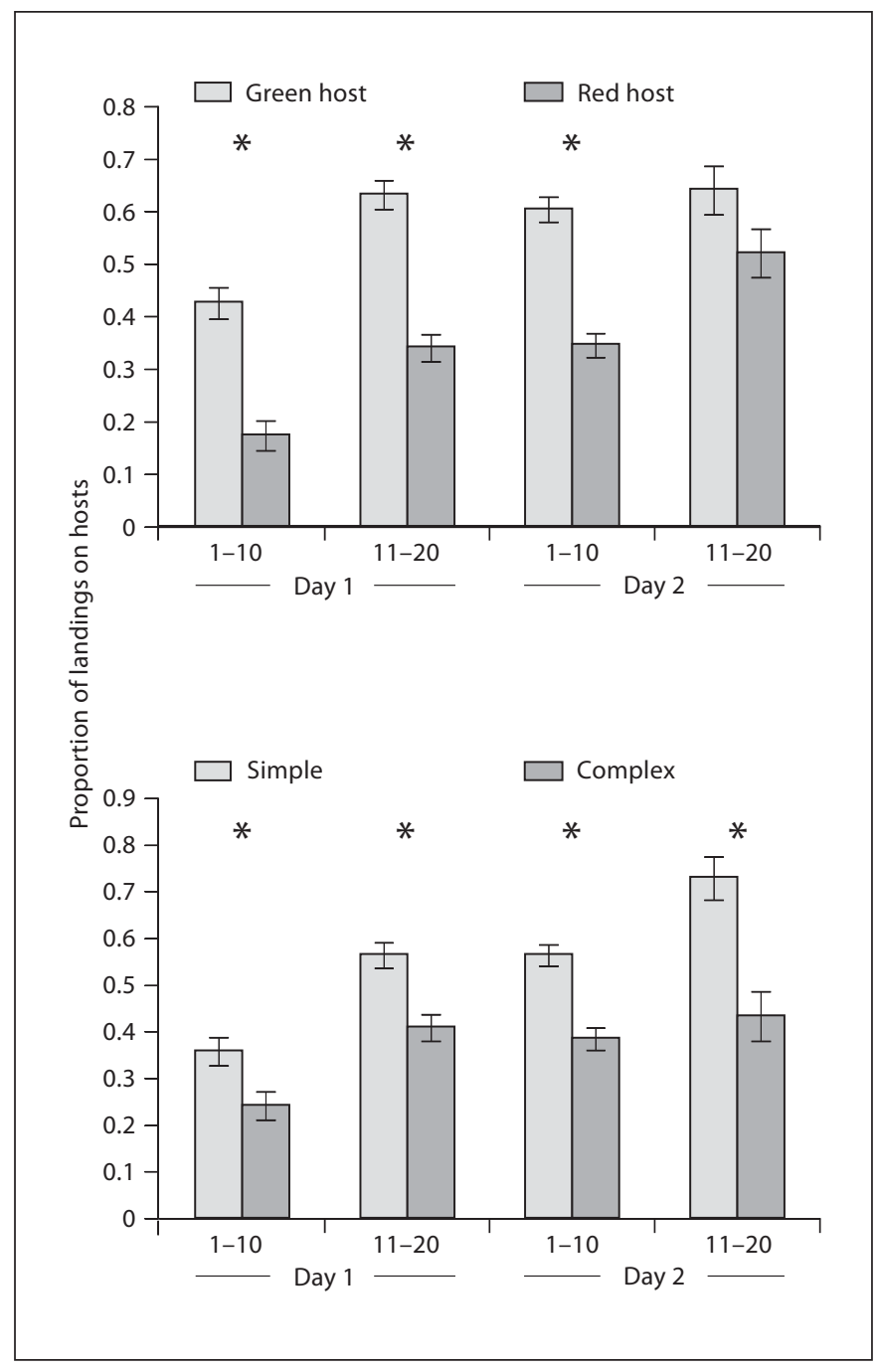

Fig. 2. Host-finding efficiency among bins of ten landings. Hostfinding efficiency was measured as the proportion of landings (in bins of ten total landings) that were on host plants. Host-finding efficiency was measured over two days for each individual butterfly, on either a red or green host, in either simple or complex non-host environment. Shown are least-square means from an analysis of variance that included host color, non-host complexity, and their interaction (Experiment 1). Asterisks indicate significant differences in host-finding efficiency between the red and green host environment or the simple and complex non-host environment.

finding efficiency was significantly higher in the green host environment, at least early in the learning process (table 2; fig. 2); host-finding efficiency was always significantly lower in the complex environment, which contained a greater density and diversity of non-host plants (table 2; fig. 2). As measured in Experiment 2, changes in 


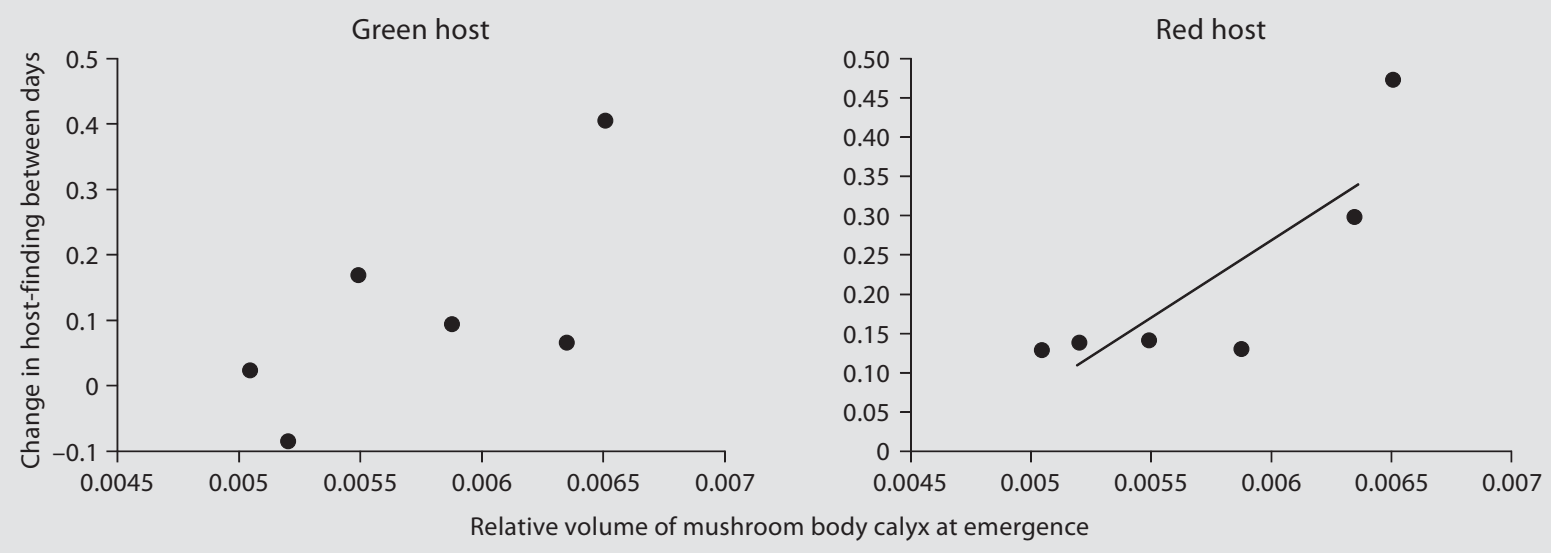

Fig. 3. A family's mushroom body size at emergence is related to their change in host-finding between days. Shown is the volume of each mushroom body calyx at emergence, relative to whole brain size, for each of 6 fullsibling families (Experiment 1). The y-axis represents each family's difference in host-finding efficiency between the two days of learning for either the red host or green host environment $(0=$ no change in host-finding efficiency; negative values indicate decline in efficiency).

Table 2. Effect of host color and non-host complexity on hostfinding ${ }^{1}$

\begin{tabular}{rlll}
\hline Landings & $\begin{array}{l}\text { Host color } \\
\left(\mathrm{F}_{1,82}\right)\end{array}$ & $\begin{array}{l}\mathrm{NH} \text { complexity } \\
\left(\mathrm{F}_{1,82}\right)\end{array}$ & $\begin{array}{l}\text { Color } \times \text { comp. } \\
\left(\mathrm{F}_{1,82}\right)\end{array}$ \\
\hline $1-10$, day 1 & $31.7^{* * *}$ & $6.14^{* *}$ & 0.09 \\
$11-20$, day 1 & $50.1^{* *}$ & $14.9^{* *}$ & $7.97^{* *}$ \\
$1-10$, day 2 & $49.8^{* * *}$ & $25.3^{* * *}$ & 0.16 \\
$11-20$, day 2 & 2.69 & $14.9^{* *}$ & 0.04 \\
\hline
\end{tabular}

${ }^{* *} \mathrm{p}<0.01 ;{ }^{* * *} \mathrm{p}<0.0001$.

${ }^{1} \mathrm{~N}=86$ individuals that participated for at least 20 landings on the first day of learning and 10 landings on the second day; Each ANOVA includes host color, non-host complexity, and color $\times$ complexity as independent variables.

host-finding efficiency were paralleled by changes in color choice [Snell-Rood and Papaj, in press]: butterflies in the red host environment chose a lower proportion of green non-hosts (versus red non-hosts) over time. In the following analyses, we measured within-day and between-day changes in host-finding efficiency and total hosts found as the average for each family (the leastsquare means from models controlling for host color,
Table 3. Effect of family and brain size or body size on brain region volume at emergence ${ }^{1}$

\begin{tabular}{lll}
\hline & $\begin{array}{l}\text { Family } \\
\left(\mathrm{F}_{5,13}\right)\end{array}$ & $\begin{array}{l}\text { Brain or body size } \\
\left(\mathrm{F}_{1,13}\right)^{2}\end{array}$ \\
\hline Calyx & $3.77^{* *}$ & 0.46 \\
Lobes & $4.12^{* * *}$ & 1.93 \\
Antennal lobes & $5.21^{* * *}$ & $16.9^{* * *}$ \\
Central body & 2.21 & $6.68^{*}$ \\
Medulla & 0.99 & $24.6^{* * *}$ \\
Whole brain & $2.79^{*}$ & $3.16^{*}$ \\
\hline
\end{tabular}

${ }^{*} \mathrm{p}<0.10 ;{ }^{* *} \mathrm{p}<0.05 ;{ }^{* * *} \mathrm{p}<0.01$.

${ }^{1} \mathrm{~N}=20$ brains from 6 families.

${ }^{2}$ Models with whole brain size included body size not brain size. Each ANOVA reported includes both family and size as independent variables.

non-host complexity, and, for measures of total hosts, total landings).

\section{Brain Size at Emergence}

At emergence, full-sibling families varied in the size of their whole brain, relative to body size, and the size of most brain regions, relative to whole brain size (table 3). There were several trends between a family's mean brain 


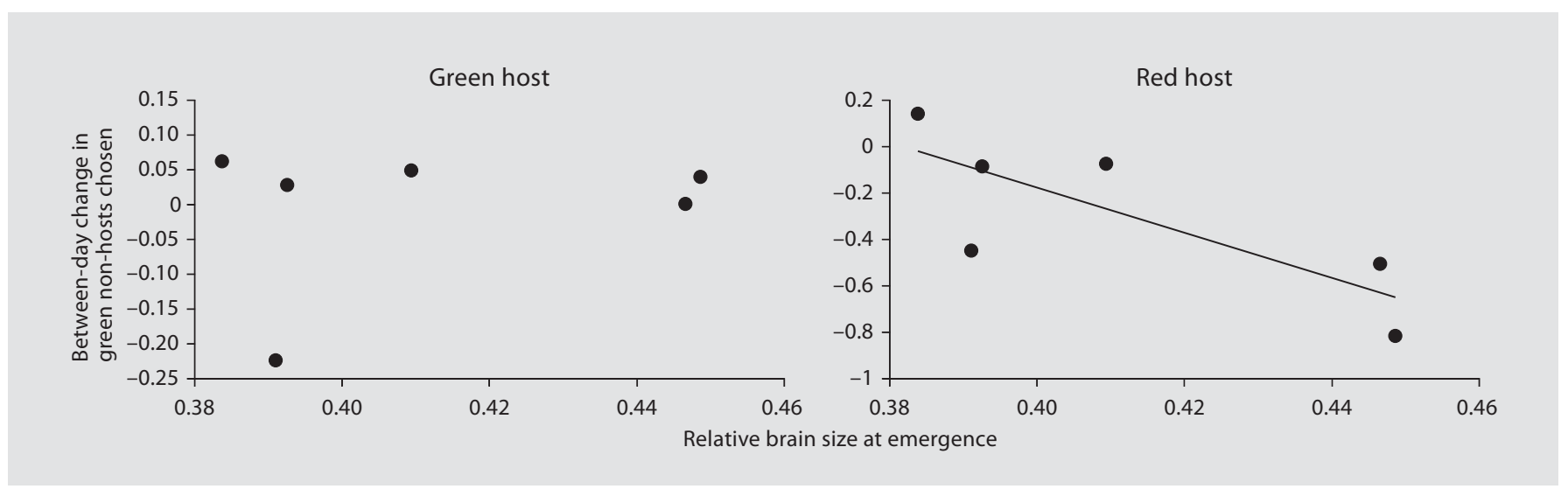

Fig. 4. A family's brain size at emergence is related to change in color choice between days. Shown are results from brains of families in an experiment (Experiment 2) designed to measure color learning as changes in the colors of non-hosts chosen between the two days of learning. Negative values indicate shifts to search for more red (as opposed to green) colors.

Table 4. Family-level relationships between host-finding ability and relative brain or brain region volume at emergence ${ }^{1}$

\begin{tabular}{llll}
\hline & $\begin{array}{l}\text { Calyx } \\
\left(\mathrm{F}_{1,4}\right)\end{array}$ & $\begin{array}{l}\text { Lobes } \\
\left(\mathrm{F}_{1,4}\right)\end{array}$ & $\begin{array}{l}\text { Whole brain } \\
\left(\mathrm{F}_{1,4}\right)\end{array}$ \\
\hline Change within, red & 1.14 & 0.28 & $4.26(+)^{*}$ \\
Change within, green & $4.31(+)^{*}$ & 0.45 & 0.76 \\
Change between, red & $9.62(+)^{* *}$ & 1.37 & 0.23 \\
Change between, green & $3.72(+)$ & $2.79(+)$ & 0.51 \\
Total hosts, red & 1.00 & 0.77 & 1.69 \\
Total hosts, green & $10.7(-)^{* *}$ & 0.03 & 0.49 \\
\hline
\end{tabular}

${ }^{*} \mathrm{p}<0.10 ;{ }^{* *} \mathrm{p}<0.05$.

${ }^{1} \mathrm{~N}=6$ families (individual ANOVAs reported). tio $>2$.

$(+)$ positive trend for $\mathrm{F}$ ratio $>2$; $(-)$ negative trend for $\mathrm{F}$ ra-

size at emergence and its host-finding ability ( $n=6$ families). Families that emerged with large mushroom body calyces, relative to whole brain size, were more likely to increase their ability to locate red hosts over the two days of learning (fig. 3; table 4). There was also a tendency for families with large mushroom body lobes, relative to whole brain size, to increase their ability to locate green hosts over the two days of learning; however, this difference was not statistically significant (table 4). There were no significant (or marginally significant) relationships between behavioral measures and the volume of the whole brain (relative to body size) or the medulla, central
Table 5. Effect of family, experience, and brain or body size on brain region volume ${ }^{1}$

\begin{tabular}{lllll}
\hline & $\begin{array}{l}\text { Family } \\
\left(\mathrm{F}_{5,47}\right)\end{array}$ & $\begin{array}{l}\text { Experience } \\
\left(\mathrm{F}_{1,47}\right)\end{array}$ & $\begin{array}{l}\text { Fam } \times \text { exp. } \\
\left(\mathrm{F}_{5,47}\right)\end{array}$ & $\begin{array}{l}\text { Brain size } \\
\left(\mathrm{F}_{1,47}\right)^{2}\end{array}$ \\
\hline Calyx & 1.42 & $35.6^{* * *}$ & $2.08^{*}$ & $22.8^{* * *}$ \\
Lobes & $2.44^{*}$ & $16.4^{* * *}$ & 0.51 & $6.41^{* *}$ \\
Antennal lobes & $2.96^{* *}$ & $14.8^{* * *}$ & 0.53 & $6.34^{* *}$ \\
Central body & $2.36^{* *}$ & $31.9^{* *}$ & $2.61^{* *}$ & $44.0^{* * *}$ \\
Medulla & 1.24 & $34.1^{* * *}$ & 0.51 & $368.8^{* * *}$ \\
Whole brain & $3.58^{* * *}$ & $6.53^{* * *}$ & $1.98^{*}$ & 0.79 \\
\hline
\end{tabular}

${ }^{*} \mathrm{p}<0.10 ;{ }^{* *} \mathrm{p}<0.05 ;{ }^{* * *} \mathrm{p}<0.01$

${ }^{1} \mathrm{~N}=60$ individuals from 6 families.

${ }^{2}$ Models with whole brain size included body size not brain size. Each ANOVA includes family, experience, family $\times$ experience, and size as independent variables.

body, or antennal lobe (relative to brain size) at emergence.

In a subsequent experiment [Experiment 2; SnellRood and Papaj, in press], we tested whether the observed relationship between neural investment and learning was due to color learning per se. In this experiment, we found that a family's mean whole brain volume at emergence (relative to body size) was significantly positively correlated with their ability to increase their search for red colors across days of host-search in the red host environment (fig. $4 ; \mathrm{F}_{5}=9.67, \mathrm{p}=0.03$ ) although not in the green host environment (fig. $4 ; \mathrm{F}_{5}=0.24, \mathrm{p}=0.65$ ). Calyx vol- 


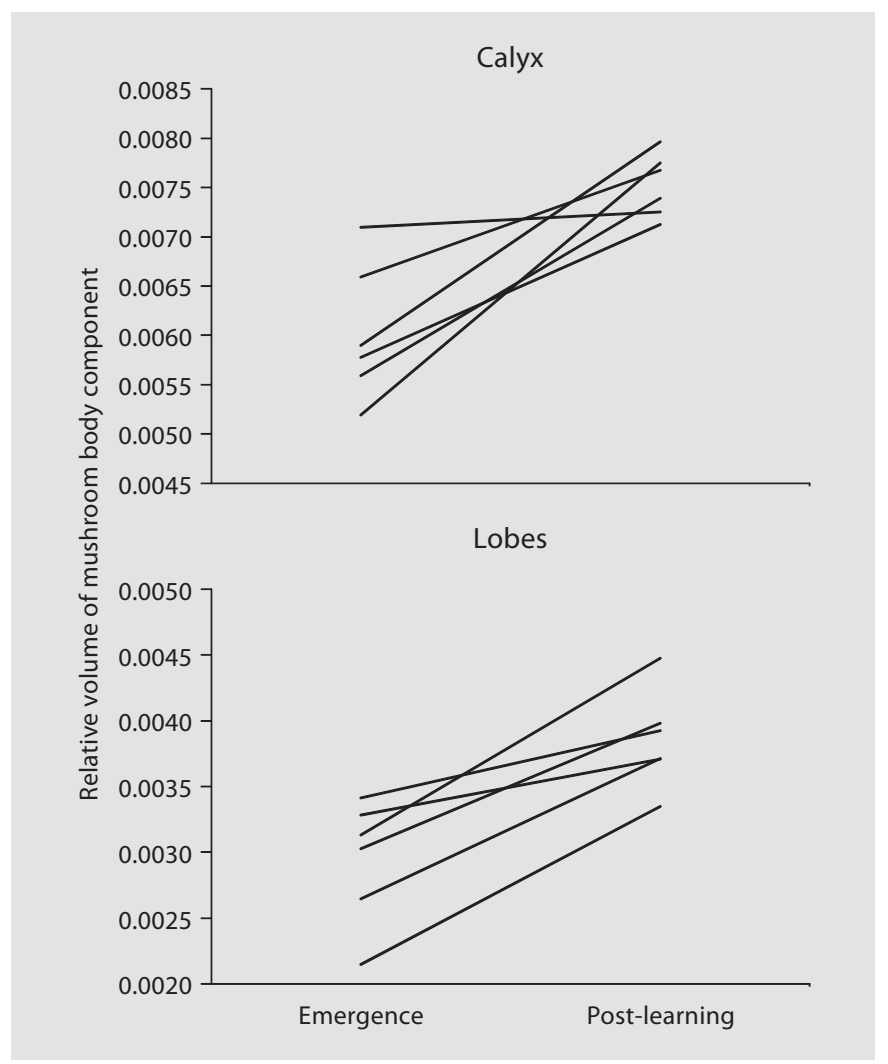

Fig. 5. Mushroom body volume increases with age and experience in a family-dependent manner. Shown are reaction norms for changes in the volume of mushroom body components relative to whole brain size. Each line represents a family of full sibling butterflies sacrificed at emergence or four days later following host experience (Experiment 1).

ume at emergence was not related to changes in color choice across days.

\section{Changes in Brains with Age and Experience}

The whole brain and each brain region were significantly larger in volume after host experience than at emergence (table 5; fig. 5; Appendix 1). Furthermore, families varied in the degree to which calyces, central body, and whole brain size increased with age and experience (age by family interaction; table 5; fig. 5).

Specific host experience was associated with changes in the relative size of some brain regions (table 6; fig. 6 , 7). The relative volume of the calyx after host experience was correlated significantly with the number of landings on foliage (table 6; fig. 7). Some brain regions showed marginally significant trends to vary with host color: the

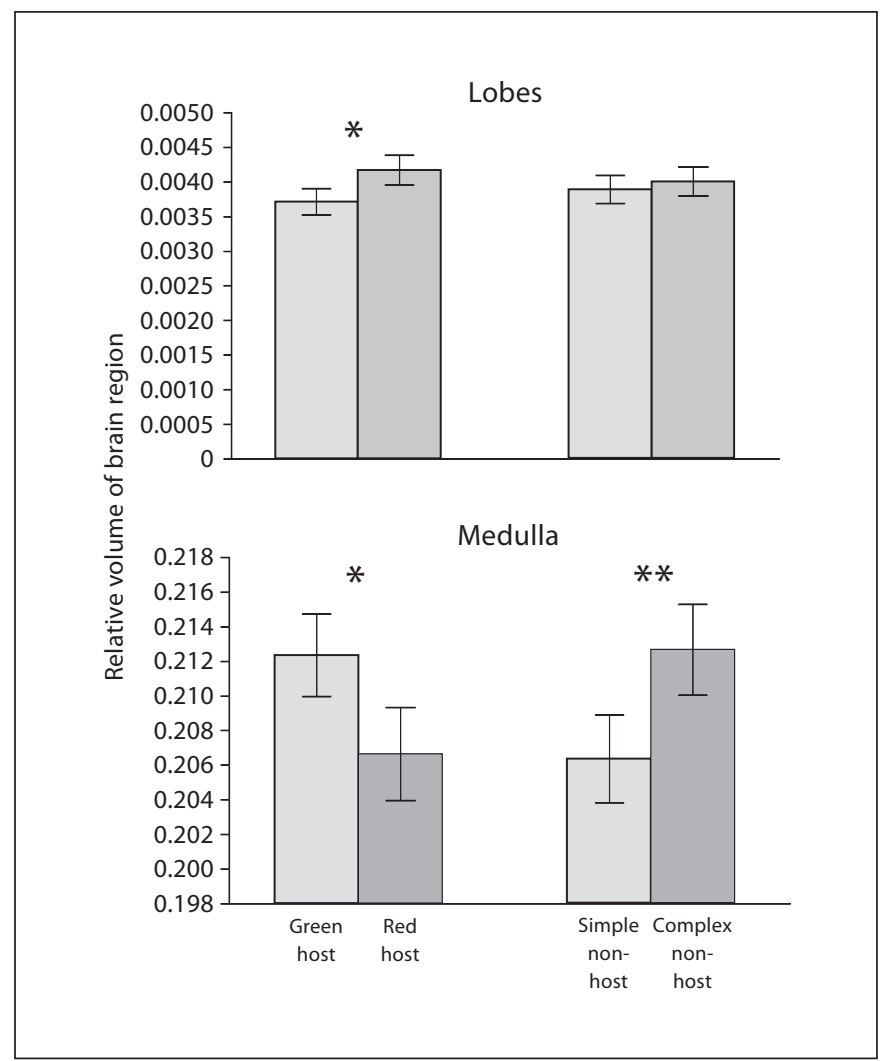

Fig. 6. Brain region volume is responsive to experience. Shown are least-square means from ANOVAs that controlled for experience (total landings), family, and whole brain size in testing for effects of host color and non-host complexity on the volume of mushroom body lobes (top) and medulla (bottom) relative to whole brain size, in individual butterflies sacrificed after host experience (Experiment 1). One asterisk indicates marginal significance $(\mathrm{p}<0.10)$, and two indicate significance $(\mathrm{p}<0.05)$.

mushroom body lobes were larger in butterflies that learned red hosts, whereas the medulla was larger in individuals that learned green hosts $(\mathrm{p}=0.06$; table 6 ; fig. 6 ). There was a significant effect of non-host complexity on the volume of the medulla, while controlling for whole brain size: individuals that experienced hosts within a complex non-host environment had a relatively larger medulla than those that experienced a simple non-host environment ( $p=0.04$; table 6; fig. 6). For subsequent analyses, we used an ANOVA (table 6) to estimate a family's brain size following host experience (as the leastsquare mean for the 'family' effect when controlling for total landings, host color, non-host complexity, and brain size or body size).

At the family-level, the relative volume of some brain regions following host experience was significantly re- 


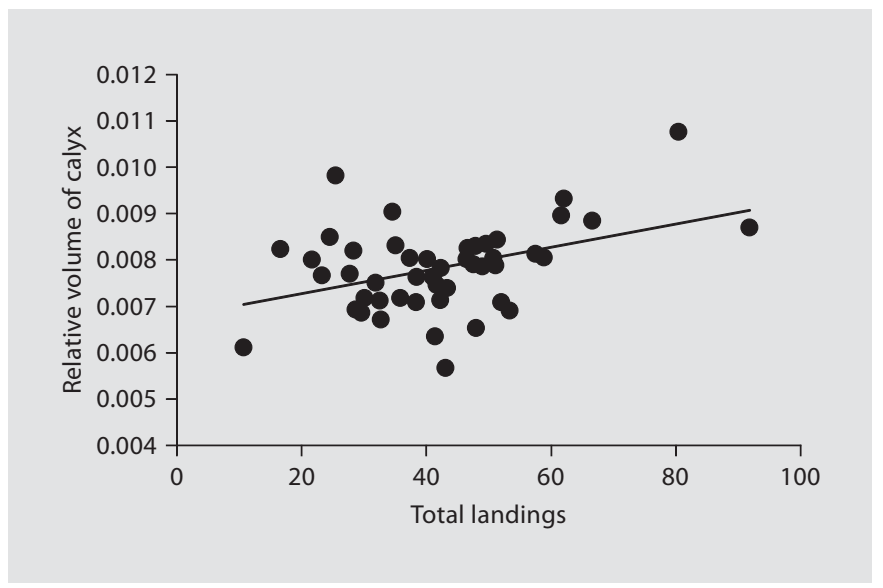

Fig. 7. Calyx volume is related to total number of landings. Shown is a leverage plot from an ANOVA controlling for family, host color, non-host complexity and total brain size. The $\mathrm{x}$-axis shows 'total landings,' the total number of host and non-host landings of an individual over the two days of host experience (Experiment 1).

lated to total hosts located, particularly in the red host environment. Families with larger calyces and antennal lobes, relative to whole brain volume, located a greater number of red hosts over their total search period (controlling for total number of landings; table 7; fig. 8). Furthermore, families with larger whole brain size (relative to body size) following experience showed greater within-day increases in host-finding in the red host environments (table 7). In a few cases, brain region size following host experience was negatively related to measures of learning (table 7).

Given that behavior is a function of brain size at emergence and subsequent growth, we wanted to ensure that family-level correlations (e.g., tables 4,7 ) were not confounded by measurements at different developmental time points. At the family-level, for the calyces, lobes, antennal lobes, and central body, the relative volume of a brain region before emergence was not correlated with its volume after host experience $(\mathrm{p}=0.56,0.23,0.96$, and 0.93 , respectively); in contrast, for medulla and whole brains the volume of a brain region after learning was positively correlated with its volume at emergence (medulla: $\mathrm{F}_{5}=6.36$, $\mathrm{p}=0.06, \mathrm{~b}=0.83$; whole brain: $\mathrm{F}_{5}=10.3, \mathrm{p}=0.03, \mathrm{~b}=1.85$ ) Thus, the relative volume of most brain regions at emergence appeared independent of their size following learning. However, we repeated significant family-level analyses from tables 4 and 7 in a model that included both a family's brain size at emergence and its brain size after

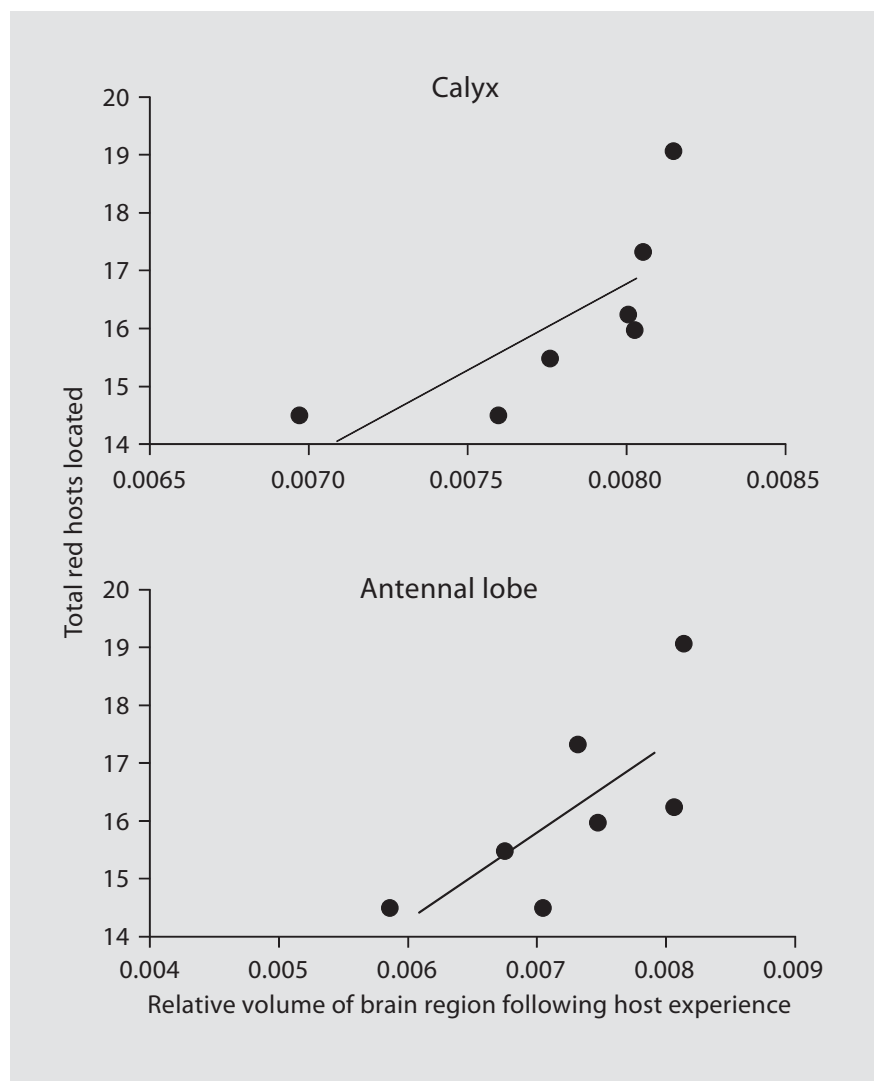

Fig. 8. The relative volume of brain regions after host experience relates to a family's ability to locate red hosts. Shown is the volume of mushroom body calyx (top) and antennal lobe (bottom) relative to whole brain size, following experience (controlling for the type and degree of experience) and its relation to total red hosts located (controlling for total landings). Each data point represents one full-sibling family (Experiment 1).

Table 6. Effect of host color, non-host complexity, brain or body size and total landings on brain region or brain volume ${ }^{1}$

\begin{tabular}{llllll}
\hline & $\begin{array}{l}\text { Host color } \\
\left(\mathrm{F}_{1,36}\right)\end{array}$ & $\begin{array}{l}\text { Complexity } \\
\left(\mathrm{F}_{1,36}\right)\end{array}$ & $\begin{array}{l}\text { Brain size } \\
\left(\mathrm{F}_{1,36}\right)\end{array}$ & $\begin{array}{l}\text { Landings } \\
\left(\mathrm{F}_{1,36}\right)\end{array}$ & $\begin{array}{l}\text { Family } \\
\left(\mathrm{F}_{6,36}\right)\end{array}$ \\
\hline Calyx & 0.13 & 0.21 & $30.1^{* * *}$ & $7.13^{* *}$ & 0.96 \\
Lobes & $3.50^{*}$ & 0.21 & $9.64^{* * *}$ & 0.66 & 1.03 \\
Antennal lbs & 0.27 & 0.71 & $6.29^{* *}$ & 0.21 & $2.19^{*}$ \\
Central body & 1.82 & 0.37 & $57.9^{* * *}$ & 1.52 & $4.64^{* * *}$ \\
Medulla & $3.43^{*}$ & $3.91^{* *}$ & $383.3^{* *}$ & 0.95 & $3.02^{* * *}$ \\
Whole brain & 0.07 & 0.05 & 1.89 & 0.99 & $2.75^{* *}$ \\
\hline
\end{tabular}

${ }^{*} \mathrm{p}<0.10 ;{ }^{* *} \mathrm{p}<0.05 ;{ }^{* * *} \mathrm{p}<0.01$

${ }^{1} \mathrm{~N}=47$ individuals from 7 families.

${ }^{2}$ Models with whole brain size included body size not brain size. Each ANOVA includes host color, non-host complexity, total landings, family, and size as independent variables. 
Table 7. Family-level relationships between host-finding ability and relative brain or brain region volume after learning ${ }^{1}$

\begin{tabular}{llllll}
\hline & $\begin{array}{l}\text { Calyx } \\
\left(\mathrm{F}_{1,5}\right)\end{array}$ & $\begin{array}{l}\text { Antennal } \\
\text { lobes }\left(\mathrm{F}_{1,5}\right)\end{array}$ & $\begin{array}{l}\text { Medulla } \\
\left(\mathrm{F}_{1,5}\right)\end{array}$ & $\begin{array}{l}\mathrm{CB} \\
\left(\mathrm{F}_{1,5}\right)\end{array}$ & $\begin{array}{l}\text { Whole brain } \\
\left(\mathrm{F}_{1,5}\right)\end{array}$ \\
\hline $\begin{array}{l}\text { Change within, red } \\
\text { Change within, green }\end{array}$ & 0.46 & 0.49 & 1.02 & 1.52 & $12.9(+)^{* *}$ \\
Change between, red & $2.77(-)$ & 1.60 & $2.86(+)$ & $4.71^{*}(-)$ & 0.06 \\
Change between, green & 0.02 & $5.18^{*}(-)$ & 0.001 & 0.93 & 0.01 \\
Total hosts, red & 0.16 & 1.81 & 0.16 & 1.92 & 0.06 \\
Total hosts, green & $6.70(+)^{* *}$ & $5.97^{*}(+)$ & 0.12 & $4.43^{*}(+)$ & $2.08(+)$ \\
\hline
\end{tabular}

${ }^{*} \mathrm{p}<0.10 ;{ }^{* *} \mathrm{p}<0.05$.

${ }^{1} \mathrm{~N}=7$ families (individual ANOVAs reported).

$(+)$ positive trend for F ratio $>2$; (-) negative trend for $\mathrm{F}$ ratio $>2$.

Table 8. Effect of age, experience and size on brain region volume

\begin{tabular}{|c|c|c|c|c|}
\hline & \multicolumn{2}{|c|}{ Experiment $2^{1}$} & \multicolumn{2}{|c|}{ Experiment 1 vs. $2^{2}$} \\
\hline & $\begin{array}{l}\text { age } \\
\left(\mathrm{F}_{1,22}\right)\end{array}$ & $\begin{array}{l}\text { brain size }{ }^{3} \\
\left(F_{1,22}\right)\end{array}$ & $\begin{array}{l}\text { exp./age } \\
\left(\mathrm{F}_{1,56}\right)\end{array}$ & $\begin{array}{l}\text { brain size }{ }^{3} \\
\left(F_{1,56}\right)\end{array}$ \\
\hline Calyx & 3.49 & 2.30 & $5.23^{*}$ & $38.5^{* * *}$ \\
\hline Lobes & 0.39 & 2.33 & $9.67^{* *}$ & $15.2^{* * *}$ \\
\hline Antennal lobes & 0.35 & 3.35 & 1.74 & $15.7^{* * *}$ \\
\hline Central body & 1.23 & $22.6^{* * *}$ & $9.37^{* *}$ & $89.2^{* * *}$ \\
\hline Medulla & 1.68 & $60.5^{* * *}$ & $8.97^{* *}$ & $335.8^{* * *}$ \\
\hline Whole brain & 3.53 & 2.86 & 0.27 & 0.25 \\
\hline
\end{tabular}

${ }^{*} \mathrm{p}<0.05 ;{ }^{* *} \mathrm{p}<0.01 ;{ }^{* *} \mathrm{p}<0.001$.

1 Comparison of brains from butterflies sacrificed at emergence to those without host experience sacrificed two days later (just prior to when others began learning).

${ }^{2}$ Comparison of brain regions of butterflies sacrificed just prior to learning (Experiment 2) to those sacrificed just following learning (Experiment 1). We were unable to collect brains of butterflies following learning in Experiment 2.

${ }^{3}$ Models with whole brain size included body size not brain size. Each ANOVA includes age or experience and brain size or body size as independent variables.

experience. Power was significantly reduced, but significant effects remained significant, or marginally so (marginally significant effects lost significance; Appendix 2).

We were interested in whether the volume differences between butterflies sacrificed at emergence and those sacrificed after learning (four days later) were primarily due to specific experiences during the period of hostsearch, or instead primarily due to normal age-related changes between emergence and the period of hostsearch. To further address this question, in a subsequent experiment [Experiment 2; Snell-Rood and Papaj, in press], we were able to sacrifice butterflies both at emergence, and just prior to when siblings began host-search (after two days of being held in greenhouse cages without host plants); unfortunately, we were not able to collect enough butterflies for analyses of brain size following learning. Most brain regions showed trends to increase between emergence and the time just before host-search, but none of these differences were significant (table 8; Appendix 1). When brain region size was compared across experiments, most brain regions (mushroom body lobes and calyces, medulla, and central body) were significantly larger in individuals sacrificed just following host experience than in those sacrificed just prior to experience (table 8; Appendix 1). However, cross-experiment comparisons can be confounded by any number of factors and must be interpreted cautiously.

\section{Discussion}

\section{Host-Learning in Butterflies}

As in other studies [e.g., Traynier, 1984, 1986], we found evidence that learning plays a role in host-finding in Pieris butterflies. In our first experiment, individual butterflies showed significant improvements in their ability to distinguish hosts from non-hosts within and across the two days of host experience (fig. 2). Results of our second experiment [Snell-Rood and Papaj, in press] suggest that at least part of this improvement is due to color learning: as host-finding efficiency in the red envi- 
ronment increases, the choice of green non-hosts decreases (and choice of red non-hosts increases). In these experiments, hosts differed not only in color, but presumably odor and other visual characteristics. Thus, butterflies are likely learning multiple cues (color, shape, odor) as they increase their host-finding efficiency over time.

We estimated a family's overall host-finding efficiency and learning ability using the 'family by host color' interaction term in models that included host color, non-host complexity, and (for measures of total hosts chosen) total landings during host-search. Other experiments have found host-finding efficiency and color choice to vary significantly between groups of full sibling Pieris rapae [Snell-Rood and Papaj, in press], so we assumed values from these models (least-square means) were good estimates of family-level behavior.

\section{Brain Size as a Global Cost of Learning}

We found that the volume of the mushroom bodies at emergence (relative to whole brain size) was related to a family's learning ability, albeit to a modest degree. Specifically, the relative size of the mushroom body calyx was related to a family's improvement in their ability to locate red hosts across two days of host-search (table 4; fig. 3). Furthermore, brains collected in a later experiment (Experiment 2), suggested that brain size at emergence (relative to body size) was related to a family's ability to increase their search for red colors across two days of host-search (fig. 4). These results suggest that brain and mushroom body size at emergence could act as a global cost of learning: individuals with the ability to improve host-search over time emerge with greater neural investment, which might exact energetic costs relative to individuals with less pronounced learning ability.

Interestingly, we found that brain size at emergence was linked to changes in host-finding ability between days, but not within days (table 4). Measures of performance on the first day of learning likely reflect both initial biases and short-term memory processes, but not long-term memory formation as trials were less than an hour in length. Long-term and short-term memory represent distinct physiological processes [reviewed in DeZazzo and Tully, 1995; Menzel, 2001; Margulies et al., 2005]; long-term memory, in contrast to short-term memory, requires protein synthesis and structural changes in neural networks [reviewed in Silva et al., 1998; Tischmeyer and Grimm, 1999; Lamprecht and LeDoux, 2004]. Thus, measures of changes in behavior across the two days of learning might be more reflective of longterm memory, which could be costlier than other forms of memory [Mery and Kawecki, 2005]. Although consistent with our observations, this interpretation is in need of further experimental support.

Links between brain component size at emergence and learning ability were not present for some brain regions measured and some measurements of learning ability (table 4). For instance, there were no correlations between learning (or total hosts located) and the relative volume at emergence of the central body, antennal lobe or medulla. These results suggest that brain size and behavior might not always be tightly linked within species. Although we did detect some global costs of learning, these costs were specific to certain brain regions (e.g., relative calyx size) and measures of learning (e.g., betweenday changes in host-finding).

\section{Brain Size as an Induced Cost of Learning}

This study found that the volume of all brain regions surveyed, when adjusted for whole brain volume, changed with age and experience, and further, that these changes were linked to host-finding behavior. All brain regions considered were relatively larger in individuals sacrificed after host experience (at age 4 days) relative to siblings sacrificed at emergence (table 5; fig. 5). Several results suggest that much of this change occurred during the time when females searched for hosts. Most importantly, in Experiment 1, some of the changes in brain size over time were correlated with specific aspects of host experience, suggesting that brain size might respond selectively to certain learning conditions, and that the changes we observed were not simply a generalized change in brain size with age (table 5, 6; fig. 6, 7). For instance, mushroom body calyx size was positively correlated with the total number of landings during host-search (table 5; fig. 7), reminiscent of other studies which have found positive effects of activity on brain development [reviewed in Cotman and Berchtold, 2002]. The mushroom body lobes showed a marginally significant tendency to be larger after experience in the red host environment relative to experience in the green host environment (table 6; fig. 6). Many studies have highlighted age- and experience-dependent changes in mushroom body size that are correlatively and causally linked to learning [Balling et al., 1987; Durst et al., 1994; Withers et al., 1995, 2007; Gronenberg et al., 1996; Farris et al., 2001]. Thus, our observed changes in the mushroom body, which receive both olfactory and visual inputs (fig. 1) [Strausfeld et al., 1998], might reflect the im- 
portance of learning or sensory integration (both color, shape and smell) during host experience. We also found that the medulla tended to be larger following green host experience and in complex non-host environments (table 6; fig. 6). The adult development of optic lobes in insects is remarkably experience-dependent within certain critical periods [Heisenberg et al., 1995; Barth et al., 1997], suggesting that our observed differences in medulla size might have functional consequences. Given that the non-hosts used in Experiment 1 were uniformly green, discriminating green hosts from among green non-hosts might have been a very visually-demanding task that promoted the development of larger visual processing regions. Similarly, the complex non-host environment - with a greater density and diversity of nonhosts - was more visually demanding than the simple environment.

At the family level, the relative volume of the brain and brain regions following host experience was significantly related to host-finding ability. For instance, families with larger calyces and antennal lobes following host experience were more likely to locate a greater number of red hosts (table 7; fig. 8). Age- and experience-dependent changes in the size of the antennal lobes is common in insects, and often coincides with periods of learning [Withers et al., 1993; Sigg et al., 1997; Brown et al., 2004; Huetteroth and Schachtner, 2005]. Thus, this latter family-level result suggests that olfactory learning might contribute to locating the red host, and provides further support for the idea that the growth of brain regions after emergence is experience-dependent.

The fact that neural volume following learning was specific to the learning experience itself suggests that brain size was dependent on experience, as has been seen in other insects [e.g., Farris et al., 2001; Seid et al., 2005; Ismail et al., 2006; Withers et al., 2007]. We also sacrificed butterflies in a subsequent experiment to try to quantify the degree to which brain size following learning was a function of experience versus earlier age-related changes. Although our inference is limited, comparisons between Experiments 1 and 2 support the idea of learning-dependent changes in brain region size. In Experiment 2, the brains of individuals sacrificed just prior to when their siblings began host-learning were not significantly larger than the brains of siblings sacrificed at emergence (table 8). Furthermore, most brain regions were significantly larger in butterflies sacrificed after the period of hostsearch (those from Experiment 1), relative to those sacrificed just before (those from Experiment 2 ; table 8). There are potential confounding factors that limit comparisons between experiments. For example, the butterflies were from different populations, but it is worth noting that, despite population origin, brain region sizes at emergence were comparable between experiments (Appendix 1). Our results thus suggest that brain size increases during the time when we measured host-learning, but confirmation of this interpretation would require experiments that included control groups that did not receive host experience, and were sacrificed at the same time as siblings that did have such experience [as in Farris et al., 2001; Ismail et al., 2006; Withers et al., 2007].

Our results, in combination with those from dozens of other studies, suggest that neural investment might often act as an induced cost of learning in insects. Regions of the insect brain, including the mushroom bodies, antennal lobes and medulla, display remarkable plasticity in size and structure [e.g., Durst et al., 1994; Heisenberg et al., 1995; Withers et al., 1995, 2007; Gronenberg et al., 1996; Heisenberg, 1998; Scotto-Lomassese et al., 2000, 2002; Farris et al., 2001; Meinertzhagen, 2001; Seid et al., 2005; Ismail et al., 2006; Kühn-Bühlmann and Wehner, 2006]. In many cases, developmental increases in brain region volume are experience-independent [Brenowitz et al., 1995; Withers et al., 1995; Fahrbach et al., 1998], which suggests such variation in brain size might act as global costs (that is, they are not specific to certain learning experiences). In many instances, however, changes in brain region volume are thought to have some experience-dependent components [often together with experience-independent components; e.g., Withers et al., 1993, 1995; Durst et al., 1994; Barth et al., 1997; Brown et al., 2004]; any experience- or learning-dependent changes would represent induced costs of learning. Indeed, genetic mutants suggest that these experiencedependent changes are causally linked to learning [Balling et al., 1987; Devaud et al., 2003]. This research adds to this body of literature in several ways. First, we observed that developmental increases in brain size, which were likely experience-dependent, were linked to specific aspects of host-learning (tables 5-7). That said, it remains unclear whether increases in brain size led to increases in host-finding efficiency, or whether high degrees of host-finding induced changes in brain size. Second, we observed genetic variation in the degree to which age and experience result in increases in the size of certain brain regions (a family by age interaction term; table 5; fig. 5). These results suggest that developmental changes in brain size, which might represent induced costs of learning, can readily evolve within butterfly populations. 
The changes we observed in brain size over development could be due to neurogenesis, which has been associated with learning and experience in a variety of systems [hemimetabolous insects: Scotto-Lomassese et al., 2002, 2003; vertebrates: Alvarez-Buylla and Kirn, 1997; Patel et al., 1997; Rochefort et al., 2002; Lindsey and Tropepe, 2006], and has been documented in adult insect mushroom bodies in several insect orders, including Lepidoptera [reviewed in Lindsey and Tropepe, 2006; Dufour and Gadenne, 2006; Sullivan et al., 2007]. Given that adult neurogenesis in Lepidoptera is thought to be limited and, where it occurs, restricted to the mushroom bodies, it is more likely that the changes in brain compartment size observed in the present study reflected the growth of neuronal arborizations and increases in synapse size and number, a common response to experience in enriched environments, or those that promote learning [e.g., van Praag et al., 2000; Farris et al., 2001; Seid et al., 2005]. Any of these mechanisms would likely result in greater metabolic demands, although the intensity of such demands might vary with mechanism, an interesting consideration for future study.

\section{The Evolution of Brain Size and Learning}

Three observations suggest that neural investment might pose only a modest constraint on the evolution of learning within species such as Pieris rapae. First, although this study found evidence that relative mushroom body size might represent a global cost of learning (table 4; fig. 3), it also found that across all the analyses performed, learning and brain size were not consistently tightly linked. There was no relationship between overall host-finding ability and measures of brain regions, or in learning and measures of other brain regions at emergence (e.g., antennal lobe, central body, etc.). It should be noted, however, that our observations are relevant to only one type of learning assay (color learning), and one measure of neural investment (relative brain region size). Future research might reveal direct energetic costs or neural tissue costs at the structural (neuron density) and ultrastructural level (e.g., synapse size and number). Other learning assays might yield further insights into these costs.

Second, developmental changes in brain size (table 5), especially those during learning itself, might reduce the overall costs of neural investment. In many cases, organisms have evolved innate biases to use common environments or resources. If learning can be selectively 'turned on' in rare environments when the innate bias is less functional, the costs of learning can be reduced, facilitat- ing its persistence [e.g., Snell-Rood and Papaj, in press]. Indeed, our butterflies have innate biases to search for green colors, and our results suggest that increases in relative mushroom body and antennal lobe volume after emergence might facilitate location of the rare red host (fig. 8). Thus, in this system, it is possible that the link between brain size and learning might possibly be due in a large part to brain size as an induced cost (a 'pay-as-yougo' pattern of investment), but because the exact functional consequences of these brain volume increases are unclear, this idea will need further study.

Finally, we observed substantial naturally-occurring family-level variation in brain size and development. Naturally-occurring populations of butterflies exhibited variation in the volume of brain regions relative to whole brain size (table 3), including the mushroom bodies, which are involved in learning. Furthermore, families of butterflies varied in developmental changes in brain size (the family by development interaction, table 5). If family-level differences reflect genetic differences (and not maternal effects), then populations might respond readily to selection on brain size, brain development, and/or learning. Taken together, our results suggest that global costs possibly vary with brain region and type of learning, and the presence of induced costs might facilitate the maintenance of variation in learning (and brain size) in natural populations.

\section{Acknowledgements}

Angelique Paulk and Andre Riveros provided guidance during the development and implementation of this work. Angelique Paulk generated the 3D-brain image (fig. 1a, b). Thanks to Alvin Jin, Anbar Najam, Bonnie Bell, and Noel Eloriaga for assistance in processing samples, and to Armin Moczek, Lisa Nagy, Goggy Davidowitz, Melanie O'Day, and two anonymous reviewers for comments on earlier versions of the manuscript. This work was supported by a grant from the Center for Insect Science at the University of Arizona to E.S.-R. and by a grant from the National Science Foundation to W.G. (IOB-0519483). 


\section{Appendix 1}

Mean relative volume ( \pm SE) of brain and brain regions at different ages and experiences (values are reported as $\times 10^{-3} \mathrm{~mm}^{3}$ )

\begin{tabular}{|c|c|c|c|c|}
\hline \multirow[t]{2}{*}{ Region } & \multicolumn{2}{|c|}{ Experiment $1^{*}$} & \multicolumn{2}{|c|}{ Experiment $2^{* *}$} \\
\hline & $\begin{array}{l}\text { emer- } \\
\text { gence }\end{array}$ & $\begin{array}{l}\text { post- } \\
\text { learning }\end{array}$ & $\begin{array}{l}\text { emer- } \\
\text { gence }\end{array}$ & $\begin{array}{l}\text { pre- } \\
\text { learning }\end{array}$ \\
\hline Calyx & $6.04(0.20)$ & $7.56(0.14)$ & $5.51(0.22)$ & $6.39(0.39)$ \\
\hline Lobes & $2.94(0.18)$ & $3.85(0.12)$ & $2.87(0.10)$ & $2.73(0.18)$ \\
\hline Antennal lobes & $5.69(0.26)$ & $6.96(0.18)$ & $5.79(0.21)$ & $6.05(0.36)$ \\
\hline Central body & $1.72(0.04)$ & $1.95(0.02)$ & $1.56(0.03)$ & $1.63(0.05)$ \\
\hline Medulla & $185(2.36)$ & $203(1.63)$ & $165(2.64)$ & $172(4.58)$ \\
\hline Whole brain & $435(12.9)$ & $477(9.07)$ & $410(9.81)$ & $445(17.8)$ \\
\hline
\end{tabular}

* Shown are least-square means from an ANOVA reported in table 5 that includes as independent variables brain size (or body size in the case of brain size as a dependent variable), family, and whether a butterfly was sacrificed at emergence or just following learning (4 days after emergence).

** Shown are least-square means from an ANOVA reported in table 8 that includes as independent variables brain size (or body size in the case of brain size as a dependent variable), and whether a butterfly was sacrificed at emergence or just prior to when other butterflies began host-searching (2 days after emergence).

\section{Appendix 2}

Effects of a family's brain size - both at emergence and following host experience - on behavior. Significant or marginally-significant relationships from tables 4 and 7 were repeated in ANOVAs that included both brain size at emergence and brain size following host experience as independent variables (at the family level)

\begin{tabular}{|c|c|c|}
\hline $\begin{array}{c}\text { Behavioral measure } \\
\text { Brain region }\end{array}$ & $\begin{array}{l}\text { Size at } \\
\text { emergence }\end{array}$ & $\begin{array}{l}\text { Size after host } \\
\text { experience }\end{array}$ \\
\hline \multicolumn{3}{|c|}{ Red host-finding ( $\Delta$ between days) } \\
\hline Mushroom body calyx & $9.90(+)^{* *}$ & 0.79 \\
\hline Antennal lobe & $2.46(+)$ & $5.68(-)^{*}$ \\
\hline \multicolumn{3}{|c|}{ Red host-finding ( $\Delta$ within day 1$)$} \\
\hline Whole brain & 1.63 & $22.9(+)^{* *}$ \\
\hline \multicolumn{3}{|c|}{ Green host-finding ( $\Delta$ within day 1 ) } \\
\hline Mushroom body calyx & $3.03(+)$ & 1.47 \\
\hline Central body & $4.64(+)$ & $3.49(-)$ \\
\hline \multicolumn{3}{|l|}{ Total red hosts located } \\
\hline Mushroom body calyx & 0.45 & $3.81(+)$ \\
\hline Antennal lobe & $2.35(+)$ & $11.3(+)^{* *}$ \\
\hline Central body & 0.001 & $3.58(+)$ \\
\hline \multicolumn{3}{|l|}{ Total green hosts located } \\
\hline Mushroom body calyx & $2.61(-)$ & 0.004 \\
\hline $\begin{array}{l}{ }^{*} \mathrm{p}<0.10 ;{ }^{* *} \mathrm{p}<0.05 \\
{ }^{1} \mathrm{~N}=7 \text { families. } \\
(+) \text { positive trend for } \mathrm{F} \\
\text { io }>2 \text {. }\end{array}$ & -) $\mathrm{r}$ & - \\
\hline
\end{tabular}

\section{References}

Ali FA (1974) Structure and metamorphosis of the brain and suboesophageal ganglion of Pieris brassicae (L.) (Lepidoptera: Pieridae). Trans R Ent Soc Lond 125:363-412.

Alvarez-Buylla A, Kirn JR (1997) Birth, migration, incorporation and death of vocal control neurons in adult songbirds. J Neurobiol 33:585-601

Balling A, Technau GM, Heisenberg M (1987) Are the structural changes in adult Drosophila mushroom bodies memory traces? Studies on biochemical learning mutants. J Neurogenet 4:65-73.

Barth M, Hirsch HVB, Meinertzhagen IA, Heisenberg M (1997) Experience-dependent developmental plasticity in the optic lobe of Drosophila melanogaster. J Neurosci 17: 1493-1504.

Basil JA, Kamil AC, Balda RP, Fite KV (1996) Differences in hippocampal volume among food storing corvids. Brain Behav Evol 47: 156-164.
Brenowitz EA, Lent K, Kroodsma DE (1995) Brain space for learned song in birds develops independently of song learning. J Neurosci 15:6281-6286.

Brown SM, Napper RM, Mercer AR (2004) Foraging experience, glomerulus volume, and synapse number: a stereological study of the honey bee antennal lobe. J Neurobiol 60:4050.

Clayton NS, Krebs JR (1994) Hippocampa growth and attrition in birds affected by experience. Proc Natl Acad Sci USA 91:74107414

Cotman CW, Berchtold NC (2002) Exercise: a behavioral intervention to enhance brain health and plasticity. Trends Neurosci 25: 295-301.

Courtney SP (1986) The ecology of pierid butterflies: dynamics and interactions. Adv Ecol Res 15:51-131.
Devaud J-M, Acebes A, Ramaswami M, Ferrús A (2003) Structural and functional changes in the olfactory pathway of adult Drosophila take place at a critical age. J Neurobiol 56: 13-23.

DeVoogd TJ (2004) Neural constraints on the complexity of avian song. Brain Behav Evol 63:221-232.

DeVoogd TJ, Krebs JR, Healy SD, Purvis A (1993) Relations between song repertoire size and the volume of brain nuclei related to song: comparative evolutionary analyses among oscine birds. Proc R Soc Lond B Biol 254:7582.

DeWitt TJ, Sih A, Wilson DS (1998) Costs and limits of phenotypic plasticity. Trends Ecol Evol 13:77-81.

DeZazzo J, Tully T (1995) Dissection of memory formation: from behavioral pharmacology to molecular genetics. Trends Neurosci 18: 212-218. 
Dufour M-C, Gadenne C (2006) Adult neurogenesis in a moth brain. J Comp Neurol 495: 635-643.

Dukas R (1998) Evolutionary ecology of learning. In: Cognitive Ecology: The Evolutionary Ecology of Information Processing and Decision Making (Dukas R, ed), pp 129-174. Chicago, IL: University Chicago Press.

Durst C, Eichmüller S, Menzel R (1994) Development and experience lead to increased volume of subcompartments of the honeybee mushroom body. Behav Neural Biol 62:259263.

Fahrbach SE, Moore D, Capaldi EA, Farris SM, Robinson GE (1998) Experience-expectant plasticity in the mushroom bodies of the honeybee. Learn Mem 5:115-123.

Farris SM, Roberts NS (2005) Coevolution of generalist feeding ecologies and gyrencephalic mushroom bodies in insects. Proc Natl Acad Sci USA 102:17394-17399.

Farris SM, Sinakevitch I (2003) Development and evolution of the insect mushroom bodies: towards the understanding of conserved developmental mechanisms in a higher brain center. Arthropod Struct Dev 32:79-101.

Farris SM, Robinson GE, Fahrbach SE (2001) Experience- and age-related outgrowth of intrinsic neurons in the mushroom bodies of the adult worker honeybee. J Neurosci 21: 6395-6404

Fry JD (1992) The mixed-model analysis of variance applied to quantitative genetics: biological meaning of the parameters. Evolution 46:540-550.

Gronenberg W (2001) Subdivisions of hymenopteran mushroom body calyces by their afferent supply. J Comp Neurol 435:474-489.

Gronenberg W, Heeren S, Hölldobler B (1996) Age-dependent and task-related morphological changes in the brain and the mushroom bodies of the ant Camponotus floridanus. J Exp Biol 199:2011-2019.

Gundersen HJG, Jensen EB (1987) The efficiency of systematic sampling in stereology and its prediction. J Microsc 147:229-263.

Healy SD, Krebs JR (1996) Food storing and the hippocampus in Paridae. Brain Behav Evol 47:195-199.

Heinze S, Homberg U (2007) Maplike representation of celestial e-vector orientations in the brain of an insect. Science 315:995-997.

Heisenberg M (1998) What do the mushroom bodies do for the insect brain? An introduction. Learn Mem 5:1-10.

Heisenberg M, Heusipp M, Wanke C (1995) Structural plasticity in the Drosophila brain. J Neurosci 15:1951-1960.

Hern A, Edwards-Jones G, McKinlay RG (1996) A review of the pre-oviposition behaviour of the small cabbage white butterfly, Pieris rapae (Lepidoptera: Pieridae). Ann Appl Biol 128:349-371.

Huerta R, Nowotny T, García-Sanchez M, Abarbanel HDI, Rabinovich MI (2004) Learning classification in the olfactory system of insects. Neural Comput 16:1601-1640.
Huetteroth W, Schachtner J (2005) Standard three-dimensional glomeruli of the Manduca sexta antennal lobe: a tool to study both developmental and adult neuronal plasticity. Cell Tissue Res 319:513-524.

Isler K, van Schaik CP (2006a) Metabolic costs of brain size evolution. Biol Lett - UK 2:557560.

Isler K, van Schaik CP (2006b) Costs of encephalization: the energy trade-off hypothesis tested on birds. J Hum Evol 51:228-243.

Ismail N, Robinson GE, Fahrbach SE (2006) Stimulation of muscarinic receptors mimics experience-dependent plasticity in the honey bee brain. Proc Natl Acad Sci USA 103: 207-211.

Johnston TD (1982) Selective costs and benefits in the evolution of learning. Adv Stud Behav 12:65-106.

Kandori I, Ohsaki N (1996) The learning abilities of the white cabbage butterfly, Pieris rapae, foraging for flowers. Res Pop Ecol 38: 111-117.

Kolb G, Scherer C (1982) Experiments on wavelength specific behavior of Pieris brassicae $\mathrm{L}$. during drumming and egg-laying. J Comp Phys 149:325-332.

Kühn-Bühlmann S, Wehner R (2006) Age-dependent and task-related volume changes in the mushroom bodies of visually guided desert ants, Cataglyphis bicolor. J Neurobiol 66: 511-521.

Lamprecht R, LeDoux J (2004) Structural plasticity and memory. Nat Rev Neurosci 5:4554

Laughlin SB, van Steveninck RRD, Anderson JC (1998) The metabolic cost of neural information. Nat Neurosci 1:36-41.

Lewis AC (1993) Learning and the evolution of resources: pollinators and flower morphology. In: Insect Learning: Ecology and Evolutionary Perspectives (Papaj DR, Lewis AC, eds), pp 219-242. New York: Chapman and Hall.

Lindsey BW, Tropepe V (2006) A comparative framework for understanding the biological principles of adult neurogenesis. Prog Neurobiol 80:281-307.

Liu G, Seiler H, Wen A, Zars T, Ito K, Wolf R, Heisenberg M, Liu L (2006) Distinct memory traces for two visual features in the Drosophila brain. Nature 439:551-556.

Mares S, Ash L, Gronenberg W (2005) Brain allometry in bumblebee and honey bee workers. Brain Behav Evol 66:50-61.

Margulies C, Tully T, Dubnau J (2005) Deconstructing memory in Drosophila. Curr Biol 15:R700-R713.

Meinertzhagen IA (2001) Plasticity in the insect nervous system. Adv Insect Physiol 28:84167.

Menzel R (2001) Searching for the memory trace in a mini-brain, the honeybee. Learn Mem 8: 53-62.

Mery F, Kawecki TJ (2005) A cost of long-term memory in Drosophila. Science 308:1148.
Michel RP, Cruz-Orive LM (1988) Application of the Cavalieri principle and vertical sections method to lung: estimation of volume and pleural surface area. J Microsc 150:117-136.

Mobbs PG (1982) The brain of the honeybee Apis mellifera: I. The connections and spatial organization of the mushroom bodies. Phil Trans R Soc Lond B 298:309-354.

Nilsson M, Perfilieva E, Johansson U, Orwar O, Eriksson PS (1999) Enriched environment increases neurogenesis in the adult rat dentate gyrus and improves spatial memory. J Neurobiol 39:569-578.

Nordlander RH, Edwards IS (1968) Morphology of the larval and adult brains of the monarch butterfly, Danaus plexippus plexippus, L. J Morphol 126:67-94.

Papaj DR (2003) Learning. In: Encyclopedia of Insect Learning (Resh VH, Carde RT, eds), pp 624-627. New York: Academic Press.

Papaj DR, Lewis AC (1993) Insect Learning: Ecology and Evolutionary Perspectives. New York: Chapman and Hall.

Papaj DR, Prokopy RJ (1989) Ecological and evolutionary aspects of learning in phytophagous insects. Annu Rev Entomol 34:315350

Patel SN, Clayton NS, Krebs JR (1997) Spatial learning induces neurogenesis in the avian brain. Behav Brain Res 89:115-128.

Pearson L (1971) The corpora pedunculata of Sphinx ligustri L. and other Lepidoptera: an anatomical study. Phil Trans R Soc Lond B 259:477-516

Pitnick S, Jones KE, Wilkinson GS (2006) Mating system and brain size in bats. Proc R Soc Lond B Biol 273:719-724.

Renwick JAA, Chew FS (1994) Oviposition behavior in Lepidoptera. Annu Rev Entomol 39:377-400.

Rochefort C, Gheusi G, Vincent J-D, Lledo P-M (2002) Enriched odor exposure increases the number of newborn neurons in the adult olfactory bulb and improves odor memory. J Neurosci 22:2679-2689.

Scotto-Lomassese S, Strambi C, Aouane A, Strambi A, Cayre M (2002) Sensory inputs stimulate progenitor cell proliferation in an adult insect brain. Curr Biol 12:1001-1005.

Scotto-Lomassese S, Strambi C, Strambi A, Aouane A, Augier R, Rougon G, Cayre M (2003) Suppression of adult neurogenesis impairs olfactory learning and memory in an adult insect. J Neurosci 23:9289-9296.

Scotto-Lomassese S, Strambi C, Strambi A, Charpin P, Augier R, Aouane A, Cayre M (2000) Influence of environmental stimulation on neurogenesis in the adult insect brain. J Neurobiol 45:162-171.

Seid MA, Harris KM, Traniello JFA (2005) Agerelated changes in the number and structure of synapses in the lip region of the mushroom bodies in the ant Pheidole dentata. J Comp Neurol 488:269-277.

Sherry DF (2006) Neuroecology. Annu Rev Psychol 57:167-197. 
Sherry DF, Jacobs LF, Gaulin SJC (1992) Spatial memory and adaptive specialization of the hippocampus. Trends Neurosci 15:298-303.

Sigg D, Thompson CM, Mercer AR (1997) Activity-dependent changes to the brain and behavior of the honey bee, Apis mellifera (L.). J Neurosci 17:7148-7156.

Silva AJ, Kogan JH, Frankland PW, Kida S (1998) CREB and memory. Annu Rev Neurosci 21: 127-148.

Sivinski J (1989) Mushroom body development in nymphalid butterflies: a correlate of learning? J Insect Behav 2:277-283.

Snell-Rood EC, Papaj DR (in press) Patterns of phenotypic plasticity in common and rare environments: a study of host use and color learning in the cabbage white butterfly, Pieris rapae. Am Nat.

Sullivan JM, Benton JL, Sandeman DC, Beltz BS (2007) Adult neurogenesis: a common strategy across diverse species. J Comp Neurol 500:574-584.

Strausfeld NJ (1999) A brain region in insects that supervises walking. Prog Brain Res 123: 273-284.

Strausfeld NJ, Hansen L, Li YS, Gomez RS, Ito K (1998) Evolution, discovery, and interpretations of arthropod mushroom bodies. Learn Mem 5:11-37.
Strauss R, Heisenberg M (1993) Higher control center for locomotor behavior in the Drosophila brain. J Neurosci 13:1852-1861.

Thorpe JR, Harvey DMR (1979) Optimization and investigation of the use of 2,2-dimethoxypropane as a dehydration agent for plant tissues in TEM. J Ultra Mol Struct R 68: 186-194.

Tischmeyer W, Grimm R (1999) Activation of immediate early genes and memory formation. Cell Mol Life Sci 55:564-574.

Tollrain R (1995) Predator-induced morphological defenses: costs, life history shifts, and maternal effects in Daphnia pulex. Ecology 76:1691-1705.

Tramontin AD, Brenowitz EA (2000) Seasona plasticity in the adult brain. Trends Neurosci 23:251-258.

Traynier RMM (1984) Associative learning in the ovipositional behaviour of the cabbage butterfly, Pieris rapae. Physiol Entomol 9: 465-472.

Traynier RMM (1986) Visual learning in assays of sinigrin solution as an oviposition releaser for the cabbage butterfly, Pieris rapae. Entomol Exp Appl 40:25-33.
Troetschler RG, Malone CM, Bucago ER, Johnston MR (1985) System for rearing Pieris rapae (Lepidoptera: Pieridae) on a noncruciferous artificial diet developed for Manduca sexta (Lepidoptera: Sphingidae). J Econ Entomol 78:1521-1523.

van Praag H, Kempermann G, Gage FH (2000) Neural consequences of environmental enrichment. Nat Rev Neurosci 1:191-198.

Webb SE, Shelton AM (1988) Laboratory rearing of the imported cabbageworm. New York Food Life 122:1-6.

Withers GS, Day NF, Talbot EF, Dobson HEM, Wallace CS (2007) Experience-dependent plasticity in the mushroom bodies of solitary bee Osmia lignaria (Megachilidae). Dev Neurobiol 68:73-82.

Withers GS, Fahrbach SE, Robinson GE (1993) Selective neuroanatomical plasticity and division of labour in the honeybee. Nature 364: 238-240.

Withers GS, Fahrbach SE, Robinson GE (1995) Effects of experience and juvenile hormone on the organization of the mushroom bodies of honey bees. J Neurobiol 26:130-144.

Zars T (2000) Behavioral functions of the insect mushroom bodies. Curr Opin Neurobiol 10: $790-795$. 